\title{
51. Induction of Pseudopregnancy in Rats by Applying Various Substances to Nasal Mucosa.
}

\author{
By Kiyoshi Takewaki and Yasuharu MiYamoto. \\ Zoological Institute, Faculty of Science, Tokyo University. \\ (Comm. by T. KomaI, M. J. A., July 12, 1949.)
}

\section{Introduction.}

In 1937, Rosen and Shelesnyak ${ }^{1}$ reported that in rats in which a silver nitrate solution had been applied to the nasal mucosa by means of a fine cotton applicator or a tuberculin syringe, prolongation of diestrus took place, and that if in the same rats the uterine mucosa was then injuried on the 4 th or the 5th day of diestrus by passing a silk thread through a uterine horn, a deciduoma was formed.

Shelesnyak and Rosen (1938)2) further studied the nature of the nasal reaction in the induction of pseudopregnancy. When the nasal mucosa had been stimulated electrically by means of a bipolar electrode, or chemically by painting or by infusing mustard oil on the mucosa, there took place the prolongation of diestrus in a few and of estrus in a greater number of cases (especially when mustard oil was used). On the contrary, when tannic acid, trichloracetic acid, or nupercaine was applied to the nose, pseudopregnancy was induced in many cases. From this, the authors concluded that by substances, such as mustard oil, which produce a vasodilation of the mucosa by stimulating nerve endings, the prolongation of estrus is produced, and that by protein-precipitants, such as tannic acid or trichloracetic acid, which make a layer of blocked tissues and eliminate nervous, vascular, lymphatic, and secretory functions from the affected part, or by local anesthetics, such as nupercaine, which depress nervous elements, the prolongation of the luteal phase is induced.

As the experiments made it clear that nervous factors are concerned in the naso-genital relationship, Rosen, Shelesnyak and

1) Rosen, S. and M. C. Shelesnyak 1937 Proc. Soc. Exp. Biol. and Med., 36, 832.

2) Shelesnyak, M. C. and S. Rosen 1938 Endocr.. 23. 58. 
Zacharias (1940) $)^{3}$ next removed both sphenopalatine ganglia in order to interrupt the nervous pathway to the nasal mucosa and found in a majority of cases the prolongation of the leucocytic phase.

In order to analyse further the mechanism involved in the nesogenital relationship some experiments were undertaken by Kazuo Ohzeki under the direction of the senior writer, in October, 1944. After his departure to the front in December they were continued by the present authors. The results thus obtained are presented in this report. We wish here to express our thanks to Professor Yô K. Okada for his continued interest in the problem.

\section{Methods.}

The substances applied to the nose were a saturated solution of chloretone, a 10 per cent solution of ethyl-urethane, a 5 per cent solution of morphine hydrochloride, 2, 5, 10, and 20 per cent solutions of cocaine hydrochloride, 10 and 20 per cent solutions of chloral hydrate, and a 80 per cent solution of ammonia water (a solution of aqua ammoniae of the Japanese pharmacopaea diluted to 80 per cent).

As the solutions of chloral hydrate and ammonia water were found to be most effective in inducing pseudopregnancy, in the control experiments these were painted on the buccal mucosa.

These solutions were applied to the nasal or buccal mucosa of the adult rats by means of a small cotton swab under light etherization. In general, the rats received the substances once a day on two consecutive days of pro-estrus and estrus in one cycle. In a few cases in which estrus continued for two days, the substances were applied on three successive days. Some animals were subjected to treatment several times at intervals. A vaginal smear was taken once a day.

In some of the rats in which diestrus was prolonged, a fine silk thread was passed through a uterine horn on the 5th day. Four days later, the animals were biopsied, and the traumatized uterus was examined and fixed in Bouin's solution for histologic study. The animals were not killed and were subjected to a further vaginal smear examination.

3) Rosen, S., M. C. Shelesnyak and L. R. Zacharias 1940 Endocr., 27, 463. 
Hypophysectomies were done by the parapharyngeal route.

\section{Results.}

\section{A. Nasal application of various substances.}

1. Saturated solution of chloretone.

The solution was painted on the nasal mucosa of eight rats. The prolongation of diestrus ensued only in one case. When the uterine mucosa was irritated by threading, typical deciduomata were formed. Diestrus continued for 17 days. In other rats the estrous cycles were not modified.

\section{Solution of ethyl-urethane.}

Six rats were treated nasally with a 10 per cent solution of urethane, but nothing peculiar happened to the cycles.

\section{Solution of morphine hydrochloride.}

A 5 per cant solution of morphine hydrochloride was applied to the nasal mucosa of six rats. Pseudopregnancy took place in one case only. Typical deciduomata were formed upon traumatization of the uterine mucosa. Diestrous smears were continued for 13 days.

\section{Solution of cocaine hydrochloride.}

The results are summarized in Table I. 2 and 5 per cent solutions seemed too weak, but 10 or 20 per cent solutions were highly toxic, and six rats died soon after treatment with these solutions.

Table. I. Effects of nasal application of cocaine hydrochloride.

\begin{tabular}{|c|c|c|c|}
\hline Rat & Concentration & Estrous cycle & Remarks \\
\hline C 2 & $2 \%$ & Not modified & \\
\hline C 4 & " & Diestrus continued for 14 days & Deciduomata formed \\
\hline C 5 & " & Not modified & \\
\hline C 6 & " & $"$ & \\
\hline C 7 & $"$ & Diestrus continued for 18 days & Uterus not irritated \\
\hline C 11 & " & Diestrus continued for 13 days & " \\
\hline C 13 & " & Not modified & \\
\hline C 14 & " & $"$ & \\
\hline C 15 & " & $"$ & \\
\hline C 16 & $n$ & " & \\
\hline
\end{tabular}




\begin{tabular}{|c|c|c|c|}
\hline Rat & Concentration & Estrous cycle & Remarks \\
\hline C 18 & $2 \%$ & Not modified & \\
\hline C $2 \mathrm{a}$ & $5 \%$ & " & \\
\hline C $18 \mathbf{a}$ & & " & \\
\hline C 3 & $2 \%$ in pro-estrus & Diestrus continued for 14 daps & Deciduomata formed \\
\hline C $5 \mathbf{a}$ & $20 \%$ & Diestrus continued for 12 days & \\
\hline C 14a & " & Diestrus continued for 16 daps & Uterus not irritated \\
\hline
\end{tabular}

5. Solution of chloral hydrate.

The results are presented briefly in Table II.

Table II. Effects of nasal application of chloral hydrate.

\begin{tabular}{|c|c|c|c|}
\hline Rat & Concentration & Estrous cycle & Remarks \\
\hline H 2 & $10 \%$ & Diestrus continued for 13 days & Deciduomata formed \\
\hline H 5 & $"$ & Diestrus continued for 12 days & " \\
\hline H 7 & $"$ & Diestrus continued for 13 days & $"$ \\
\hline H 11 & $"$ & Diestrus continued for 12 days & Uterus not irritated \\
\hline H 19 & $"$ & Not modified & \\
\hline H 26 & " & " & \\
\hline $\mathrm{H} 30$ & $"$ & Diestrus continued for 12 days & Deciduomata formed \\
\hline H 34 & " & Diestrus continued for 21 dars & " \\
\hline H 35 & $"$ & Diestrus continued for 13 days & Uterus not irritated \\
\hline
\end{tabular}

In seven of nine treated rats diestrus was prolonged and upon mechanical stimulation of uterine mucosa deciduomata were readily formed.

\section{Ammonia water.}

As is shown in Table III, in five of six rats prolongation of diestrus took place after the infusion of the nasal mucosa with ammonia water. In the rat A 24 no deciduomata developed in the injured uterus. On microscopical examination, however, it was found that the thread had been passed through the peripheral muscle, so the mucosa proper bad not been injured.

Table III. Effects of nasal application of ammonia water

\begin{tabular}{|c|c|c|c|}
\hline Rat & Concentration & Estrous cycle & Remarks \\
\hline A 3 & $80 \%$ & Not modified & \\
\hline A 5 & " & Diestrus continued for 10 days & Uterus not irritated \\
\hline A 9 & " & Diestrus continued for 13 days & Deciduomata formed \\
\hline A 18 & " & Diestrus continued for 12 days & \\
\hline A. 24 & " & Diestrus continued for 19 days & $\begin{array}{l}\text { No deciduomata } \\
\text { formed }\end{array}$ \\
\hline A 25 & " & Diestrus continued for 16 days & $\begin{array}{l}\text { Deciduomata formed } \\
\text { Iormed }\end{array}$ \\
\hline
\end{tabular}




\section{B. Buccal application of chloral hydrate.}

When the solutions were infused on the nasal mucosa, it was possible that some of the solution might reach the buccal cavity. It seemed, therefore, desirable to study the effects of painting the solutions directly on the buccal mucosa.

In 14 cases, a 10 per cent solution, and in two cases, a 20 per cent solution of chloral hydrate was applied to the buccal cavity, but the prolongation of diestrus was never obtained.

\section{Ovariotomy in prolonged diestrus.}

The sensitization of the uterine mucosa of rats to mechanical stimulation by infusing various substances in the nose is in all probability due to the promotion of the activity of corpora lutea. But the possible direct effects on the uterus of the substances given, that is, the effects exerted without the intermediary action of the ovary, are not excluded.

Therefore, ovariotomy was performed on the 5th day of diestrus upon a series of rats in which diestrus had been prolonged by applying nasally chloral hydrate solution or ammonia water. Immediately after spaying, the uterine horn was threaded. Four days later, the rats were killed, and the traumatized uterine horn was examined carefully.

For this purpose, (1) in nine cases a 10 per cent solution, (2) in three cases a 20 per cent solution of chloral hydrate, and (3) in nine cases an 80 per cent solution of ammonia water was applied to the nasal mucosa.

Upon examining vaginal smears, it was found that in three of group 1, in two of group 2, and in six of group 3, diestrus was prolonged at least up to five days, and on the 5th day ovariotomy and uterine traumatization were done. When killed four days later, however, none of them gave evidence of deciduomata.

The results indicate that without ovaries chloral hydrate or ammonia water cannot sensitize the uterine mucosa to mechanical irritation, that is, the substances activate the corpora lutea to secrete the hormone, which in turn sensitizes the uterus. 
One treated with 20 per cent chloral hydrate solution and one with ammonia water died soon after treatment.

\section{Hypophysectomy in prolonged diestrus.}

The next point to determine is the rôle of the anterior hypophysis in the naso-genital relationship. Can the substances such as chloral hydrate or ammonia act without the intermediary action of the anterior hypophysis upon the ovary? Or do the substances stimulate the anterior hypophysis to secrete luteotropic (or mammotropic) hormone, which in turn activates corpora lutea in the ovary?

To settle the question, some rats, treated nasally with a 20 per cent solution of chloral hydrate or an 80 per cent solution of ammonia water, were hypophysectomized on the 5th day of diestrus, and immediately after, were subjected to traumatization by passing a silk thread through a uterine horn. Four days later the rats were killed.

For unknown reasons, the results yielded by this series were not very satisfactory. Of ten chloral hydrate-rats, five, and of 16 ammonia-rats only two showed prolongation of diestrus. All of these seven rats were then subjected to hypophysectomy and uterine traumatization. At autopsy performed four days later, none of them gave the decidual reaction.

Five ammonia-rats and three chloral hydrate-rats died within a few days after the treatment.

\section{Discussion and Summary.}

It is not yet cleary known how the substances used in the experiments described in this paper act upon the nasal mucosa. Chloretone, morphine hydrochloride, cocaine hydrochloride, and chloral hydrate may possibly exert a depressing effect on nervous elements of the nasal mucosa. Ammonia water may attack the tissues of the mucosa and kill them. It seems to act as a stimulant upon the nervous elements.

The experiments have shown that the sensitivity of the uterus to mechanical irritation in the rats subjected to nasal treatment is entirely dependent upon the presence of corpora lutea and it can be prevented by the removal of both ovaries. The removal of hypophysis 
has also a similar effect in preventing the response of the uterus to mechanical stimulation.

The results therefore make it clear that the substances applied to the nasal mucosa stimulate the anterior hypophysis to secrete luteotropic hormone which in turn activates corpora lutea to function.

The chief results may be summarized as follows:

1. If a solution of chloretone, cocaine hydrochloride, morphine hydrochloride, chloral hydrate, or ammonia water is infused on the nasal mucosa of rats, prolongation of diestrus is induced, and deciduomata are produced most readily when the uterus is stimulated mechanically on the 5th day. Among the substances mentioned above, chloral hydrate and ammonia water are the most effective.

2. Chloral hydrate and ammonia water are unable to induce pseudopregnancy when painted on the buccal mucosa.

3. The effects of the substances are offset by the removal of the hypophysis or of both ovaries. It should be concluded that the substances stimulate the anterior hypophysis, which in turn activates corpora lutea to develop and function. Induction of pseudopregnancy is, therefore, the last link of the chain of events. 